\title{
PERSPECTIVE
}

\section{At-home Chemotherapy Infusion for Patients with Advanced Cancer in Hong Kong}

\author{
SSS Mak ${ }^{1}$, PE Hui ${ }^{1}$, WMR Wan ${ }^{1}$, CLP Yih ${ }^{2}$ \\ ${ }^{I}$ Department of Clinical Oncology, Prince of Wales Hospital, New Territories East Cluster, Shatin, Hong Kong \\ ${ }^{2}$ Department of Surgery, Prince of Wales Hospital, New Territories East Cluster, Shatin, Hong Kong
}

\begin{abstract}
This article reviews the development of home-based chemotherapy for patients with advanced cancer in Hong Kong, highlighting the evolution of chemotherapy infusion devices, practice, and service provision over the past decades. Further, we provide directions regarding service provision, practice, and training. At-home delivery of chemotherapy infusions has been used in the treatment of advanced colorectal and pancreatic cancers. It received positive feedback from patients and had a positive impact on the healthcare system. The model for at-home chemotherapy infusion could be further promoted and developed in patients with advanced cancer through several means. These could include exploring the feasibility of more ambulatory home chemotherapy treatment; developing protocols and selection criteria to guide who should be treated where, how to manage drug toxicity and the expected side-effects, and assessment of the self-care capabilities of patient and family; and establishing logistics through multidisciplinary collaboration, chemotherapy nursing clinics, and development of expertise to more efficiently provide resources and staffing to support at-home chemotherapy infusion. Recognising these challenges, in the future, it would be helpful to identify new and more advanced practice foci and training initiatives to meet the increased needs of the rising service load and the population's need for ongoing access to chemotherapy service.
\end{abstract}

Key Words: Catheterization, central venous; Chemotherapy, adjuvant / methods; Home infusion therapy; Infusion pumps; Nurses

\section{中文摘要}

\section{香港晚期癌症患者居家化療輸注}

\author{
麥素珊、許斌、溫偉文、葉春菱 \\ 本文回顧在香港為晚期癌症患者提供以居家為基礎的化學治療之發展, 強調過去數十年在化療藥物 \\ 輸注儀器、技術實踐及提供服務的發展。此外, 本文描述有關服務、實踐和培訓的發展方向。居家
}

Correspondence: Ms SSS Mak, Department of Clinical Oncology, Prince of Wales Hospital, New Territories East Cluster, Shatin, Hong Kong

Email:mss692@ha.org.hk

Submitted: 14 Dec 2019; Accepted: 25 Mar 2020.

Contributors: All authors designed the study. SSSM acquired the data. All authors analysed the data analysis, drafted the manuscript, and critically revised the manuscript for intellectual content. All authors had full access to the data, contributed to the study, approved the final version for publication, and take responsibility for its accuracy and integrity.

Conflicts of Interest: All authors have disclosed no conflicts of interest.

Acknowledgement: This article is based on a presentation given at the 8th Joint Scientific Meeting of The Royal College of Radiologists \& Hong Kong College of Radiologists and 27th Annual Scientific Meeting of Hong Kong College of Radiologists 2019, held in Hong Kong, China.

Funding/Support: This research received no specific grant from any funding agency in the public, commercial, or not-for-profit sectors. 


\begin{abstract}
輸注化療的方式已用於治療晚期結直腸癌和胰腺癌, 並得到了患者正面的反饋, 同時對醫療保健系 統產生正面的影響。可通過多種途徑進一步推廣及發展晚期癌症患者居家化療輸注模式。這些途徑 包括探究更多流動性居家化學治療的可行性；制定規程及選擇標準以指導誰應該在哪裡進行治療, 如何處理藥物毒性及預期副作用, 以及評估患者及家庭的自我護理能力; 並通過多學科合作、化療 護士診所及專門技術構建後勤保障, 以更有效地提供資源和人員配備以支援居家化療輸注。認識到 這些挑戰將有助於今後確定新的和更先進的實踐目標以及培訓舉措, 以滿足正在上升的服務負荷及 民眾對持續獲得化療服務不斷增加之需求。
\end{abstract}

\section{INTRODUCTION}

Historically, infusional chemotherapy for patients with cancer has been delivered in hospitals. Over the past two decades, chemotherapy practice in Hong Kong has undergone a shift from inpatient to outpatient chemotherapy, including delivery of home chemotherapy. This shift has been partly driven by the increasing incidence of cancer, with new cases hitting a record high of 33075 in $2017^{1}$ and is projected to increase by around 35\% to more than 42000 new cases per annum by $2030 .^{2}$ Inpatient chemotherapy treatment may be required for intensive, complex chemotherapy regimens that can induce severe complications. Such complications can include bone marrow failure, prolonged neutropenia, renal toxicity, and tumour lysis syndrome in bulky tumours. Inpatient treatment may also be required for unstable disease that imminently requires chemotherapy or in situations that require hospitalisation for rigorous monitoring and intervention. However, most other chemotherapy treatments are implemented on an outpatient basis, and the proportion of outpatient treatment is increasing rapidly over time. This has resulted in an overwhelming demand for oncology services and hospital beds.

As oncology centres across some clusters are already delivering chemotherapy services at full capacity, the increasing demand for services is straining the Hospital Authority's service capacity. Future demand for services is likely to increase further; improving access to anticancer drugs, improving cancer survival, and an ageing population are likely to be the key factors causing this increase. For hospitals without the resources to appropriately expand their capacity in terms of either staffing levels or physical space, it is likely that future patients will face longer waiting lists or reduced service. Reducing the use of both inpatient beds and ambulatory day beds for long infusions may help to create capacity and enhance the cost-effectiveness of the health system., ${ }^{3,4}$

Home infusion of certain medications such as chemotherapy, ${ }^{5}$ opioids, ${ }^{6}$ and antibiotics ${ }^{7,8}$ is becoming a widely used alternative to in-hospital treatment. Especially in patients with advanced cancer who tend to be physically fit but receive prolonged chemotherapy, home chemotherapy provides an opportunity to receive treatment in the comfort of their homes and the feasibility to interact much more freely with relatives.

Despite its early use in a few local settings, the development of home chemotherapy infusion is still limited. The 27th Annual Scientific Meeting of Hong Kong College of Radiologists 2019 warranted a review of home-based chemotherapy for patients with advanced cancer in Hong Kong. The focus of this article is the evolution of chemotherapy infusion devices, practice, and service provision in Hong Kong. We aim to present a picture of the developments in the field and provide directions for future service provision, practice, and training.

\section{CHEMOTHERAPY INFUSION AT HOME MODEL}

There are two commonly cited definitions of 'chemotherapy at home'. One refers to any type of administration of chemotherapeutic agents at home (eg, intravenous, subcutaneous, oral), with or without on-site supervision by a nurse. ${ }^{9}$ The other definition refers to a service package of chemotherapy-related care provided by specialist healthcare professionals (usually nurses) at the patient's home. ${ }^{10}$

Home chemotherapy can be further categorised as totally at-home or partially at-home service. For totally at-home service, the entire process is carried out in the home setting, for example, short-term infusions delivered at home by a nurse or injections delivered by parents to a child with cancer. For partially at-home service, the first chemotherapy infusion is given in the hospital or clinic, and later courses or cycles are completed at home and/or when some hospital or clinic visits are still required to initiate chemotherapy and disconnect the infusion pump. 
The partially at-home service model is more applicable for home chemotherapy infusion in Hong Kong because of the city's geographical size and the fact that no nurses currently administer chemotherapy at patients' homes. An example of partially at-home service is multi-day continuous infusion started by a nurse at the hospital, continued without the nurse's presence at home, and finished with disconnection of the pump at the hospital, which is the common practice of oncology centres in Hong Kong.

A recent review ${ }^{5}$ supported the provision of home-based chemotherapy as a safe and patient-centred alternative to hospital and outpatient-based service. Even though home-based chemotherapy has been proven feasible, and is facilitated by means of policies in a few countries, consensus on the best and most cost effective way of its administration is still lacking. ${ }^{11-15}$ Administration of chemotherapy in the home setting varies across different regions of the country, and there is no standard model that suits all situations. Successful services are tailored to match local requirements and available resources.

\section{DEVELOPMENT OF HOME CHEMOTHERAPY INFUSION SERVICE IN HONG KONG \\ Early Experience}

Implantable long-term venous, epidural, or intrathecal catheters and electronic ambulatory pumps with injection ports either totally implanted or tunnelled under the skin to convenient sites, are commercially available. Thus, at-home infusion of various medications such as chemotherapy agents or spinal morphine ${ }^{6}$ for patients with cancer has become feasible. In the 1990s, individual oncology centres used these devices for continuous infusion of chemotherapeutic agents via the portal vein for treatment of colorectal cancer with liver metastases and for intravenous infusion of the VAD combination chemotherapy regimen (vincristine, doxorubicin, dexamethasone) in the treatment of multiple myeloma.

As experience accumulated, the technique was piloted in Prince of Wales Hospital in 2005 for adjuvant treatment with a 5-fluorouracil (5FU)-based long-infusion regimen. A cohort study ${ }^{16}$ in 102 patients with colorectal cancer demonstrated considerable quality-of-life benefits with ambulatory home infusion via an electronic pump as compared with inpatient infusion of chemotherapy. That study also observed reduced treatment delays due to the lack of inpatient beds, giving cancer patients the option of receiving chemotherapy at home in Hong Kong.

\section{Promising Benefits and Impact of Current Service}

The use of implantable venous ports and portable infusion devices in home chemotherapy has become part of the standard treatment with 5FU-based regimens for various types of cancer, including colorectal and pancreatic cancer. These include combination chemotherapy regimens, such as FOLFOX (folinic acid, 5FU, oxaliplatin) or FOLFIRI (folinic acid, 5FU, irinotecan), with or without anti-epidermal growth factor receptor antibodies such as cetuximab, or panitumumab, or vascular endothelial growth factor A inhibitor such as bevacizumab.

Both inpatient and outpatient bed days can be saved by modifying the drug delivery of FOLFOX/FOLFIRI to occur in the outpatient setting. The 3-hour infusion of oxaliplatin/irinotecan \pm cetuximab and $5 \mathrm{FU}+$ folinic acid can be administered in a day centre, followed by a 46-to48-hour infusion of 5FU at home using an ambulatory pump. This obviates the need for hospitalisation and reducing bed occupancy in day centres, which could help to reduce hospital workload and related costs. ${ }^{3}$ The number of saved inpatient bed days is at least 2 days per cycle of FOLFOX/FOLFIRI. This could make a large impact given the accumulating numbers of patients requiring this treatment. Increasing day chemotherapy attendance for home chemotherapy infusion has been demonstrated with the implementation of the ambulatory home chemotherapy programme at an oncology centre. ${ }^{17}$ Reduced inpatient and outpatient bed occupancy enables hospital beds to be reallocated to patients with a greater need for inpatient care, such as those requiring more intensive care, palliative care, or chemotherapy treatments not indicated for home infusion.

Home chemotherapy has been increasingly employed in oncology centres that have been able to establish adequate logistics and technical support, and staff training. A study conducted between 2017 and 2019 involving 24 cancer patients at Pamela Youde Nethersole Eastern Hospital ${ }^{18}$ described the authors' experience with home ambulatory chemotherapy using elastomeric infusion pumps. They concluded that home ambulatory chemotherapy is safe and effective, that patients enjoy high levels of satisfaction during treatment, and that such a valuable service should be promoted more liberally in hospitals to improve the quality of patient service.

\section{Home Chemotherapy Infusion for Advanced Cancers}

Chemotherapy remains the mainstay treatment for 
patients with advanced malignancy in developed countries. Patients with advanced cancer survive longer, have more treatment options, and adhere to treatment much longer on new generations of chemotherapy, targeted therapy, and immunotherapy than they did before. Home-based oncological care is generally reserved for end-of-life patients in Hong Kong. Because management of chemotherapy-related side-effects has improved and new, safe treatment schedules and administration tools have been introduced, home-based chemotherapy is becoming a valid alternative to hospitalbased treatment for patients with advanced cancers.

Additionally, with hospitalisation, patients tend to participate less in their own care and are less ambulant because of the lack of spacing, thus disrupting the patients' normal daily hygiene and exercise routine. Patients with advanced cancer, who are at particularly high risk for nosocomial infections ${ }^{19}$ and thromboembolism, ${ }^{20}$ tend to benefit tremendously from home-based chemotherapy, as those conditions are likely to be exacerbated by hospitalisation. In addition, many patients prefer to spend time with their families rather than in hospitals.

In 2018, a survey of 22 patients with metastatic colorectal or pancreatic cancers receiving 5FU-based home infusion revealed a high level of satisfaction in the patient group. ${ }^{17}$ Two of the patients encountered minor equipment troubles during one treatment cycle, which were solved before they left the hospital. None experienced adverse events during chemotherapy infusion at home. Moreover, advantages expressed by the patients and their caregivers included the ability to continue many daily activities and to participate in their own care, giving them a greater sense of control over their treatment.

\section{CORE ELEMENTS OF IMPLEMENTING AMBULATORY HOME CHEMOTHERAPY Multidisciplinary Collaboration}

The outpatient and home settings are not necessarily panaceas for cost savings and efficiency because of the growing number of toxic treatments and complex interventions. The emphasis must be on high-quality multidisciplinary collaboration, especially in highvolume centres.

Multidisciplinary collaboration is crucial for the provision of ambulatory home chemotherapy to patients. Smooth service delivery requires the establishment of protocols and guidelines that provide a well-structured mechanism with clearly defined workflow involving oncologists, vascular surgeons, nurses and pharmacists, together with good communication among team members.

The most common problems during chemotherapy delivered via peripheral cannulation are thrombophlebitis and pain. Reliable central venous access is crucial for patients who need continuous infusion of chemotherapy at home. To facilitate home chemotherapy, implantation of a central venous catheter is needed to allow concentrated drugs to directly enter a central vein and become rapidly diluted by blood. This protects the peripheral blood vessel walls from drug irritation, solving the problems of drug extravasation and pain. Support from other teams such as vascular surgery or interventional radiology for placement of central venous access devices (CVADs) is crucial for this service.

\section{Portable Infusion Devices}

There are two types of portable infusion devices: programmable infusion pumps (electronic) and elastomeric infusion pumps (non-electronic) [Figure 1].

Electronic pumps usually operate via peristaltic mechanisms that propel the infusion forward via appendages that move in waves. Decimal rate values are programmed into the pump to provide either intermittent or continuous infusions, imparting additional flexibility to the delivery of various medications and chemotherapy regimens to treat many diseases and conditions, from haematological malignancy to chronic pain. These pumps usually contain audible and visual alarms to alert users about errors such as occlusion, low battery status, and pump malfunction. The programming of these pumps is considered to be one of the procedure's risks because of the potential for user error. In addition, electronic pumps are often sensitive to radiation exposure and can result in pump malfunction for patients on concurrent chemoirradiation therapy. ${ }^{21}$

Elastomeric pumps have no buttons for programming and rely on an elastomeric membrane to generate pressure that moves the fluid out of the membrane. The single rate of infusion is controlled by an inline orifice or flow restrictor. These pumps have benefits over the electronic ones, such as minimised risks related to pump programming, lack of noise, lightweight design, and simplified use. However, the lack of an alarm system can be risky. Besides, the accuracy of the infusion time can fluctuate greatly because of factors like temperature and 


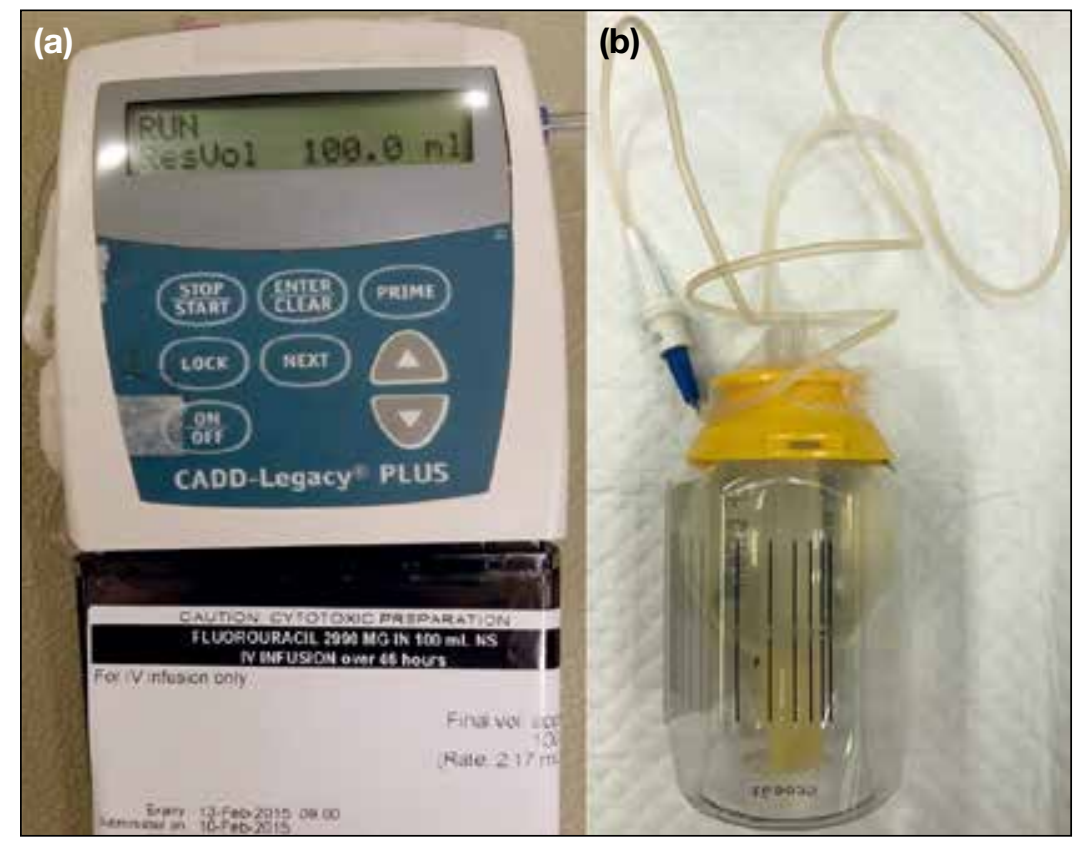

Figure 1. Portable infusion devices used in ambulatory home chemotherapy: (a) programmable ambulatory pump, (b) elastomeric infusion pump. viscosity: one study ${ }^{22}$ showed that $40 \%$ of elastomeric pumps had excess solution left upon disconnection.

Neither type of pump is absolutely free of risk nor universally fit across different regimens. Important factors for the decision of pump type include the complexity of chemotherapy, patients' pump troubleshooting ability, and the pump's weight, availability, and cost.

\section{Chemotherapy Nurse Training and Practice Review}

Chemotherapy nurses ${ }^{23}$ are usually the staff members who assess and ensure venous access and deliver chemotherapy to patients. Appropriate pretreatment assessment, patient education, and infusion monitoring are critical to patients on chemotherapy. Their duties include handling the portable infusion device, manipulating the CVAD, troubleshooting, emergency management, and the removal of chemotherapy materials. Although chemotherapy nurses handle the bulk of patient care, they also need to ensure that patients always adhere to care and safety policies. To ensure the smooth operation of the ambulatory home chemotherapy service, the relevant extra training, audits, practice review, and updates on related issues are indispensable.

\section{Patient and Caregiver Counselling and Education}

Chemotherapy nurses are not typically present at the patient's home throughout the infusion. To enable patients and their caregivers to better cope with home chemotherapy administration, assessment and counselling are provided at the chemotherapy nurse clinic. Topics include management of treatmentinduced side-effects and symptoms, at-home care of the implanted CVAD and ambulatory infusion device, simple troubleshooting, and management of emergencies such as drug spillage or disconnection of the tubes. The nurses also provide patients with a list of 'do's and don'ts' to follow while on home chemotherapy.

The major concern raised by patients and their caregivers has been the availability of support and consultation to help them when they encounter problems during at-home chemotherapy administration. Patients and caregivers should be educated about when to call, the total dose they are receiving, how long the infusion should last, the need to occasionally check the remaining drug volume in the pump, how to protect their devices while showering, and where to position the pump and catheter while sleeping. Importantly, a dedicated number is provided for patients to call in case of emergencies, and a nurse from a day centre or ward will respond anytime, even during nonoffice hours, to address any enquiries about the pump.

\section{Selection of Patient and Vascular Access Device}

Many patients receiving chemotherapy regimens 
involving 5FU may be eligible for home infusion therapy. The patients or their caregivers need to have sufficient mental and cognitive fitness and demonstrable self-care capabilities. There is no financial means assessment. Home chemotherapy is generally not advisable for patients who have poor cognitive function, learning problems, poor/unstable living environments, or no telephone access. Elderly patients living alone are eligible as long as they meet the aforementioned criteria and have access to phone calls in case of emergencies.

Several factors can guide the selection of the most appropriate CVAD for each clinical situation. If frequent blood taking is required, a double-lumen catheter is more appropriate. The Hickman catheter is preferred for haematology-oncology patients. If patients require stem cell apheresis, catheters with a wider lumen are needed. The implantable port (Figure 2) is inserted completely under the skin. Hence, it allows patients to carry out normal daily activities, such as showering, more conveniently, although it requires surgical insertion and stitching of the incision wound. The peripherally inserted central catheter (PICC) has the advantage that insertion can be performed at the patient's bedside, which provides greater flexibility in scheduling. The PICCS are designed to be used up to 12 months, and most PICCs may stay in place and in use for several months.

Patients who are prescribed chemotherapy using the home infusion model are sent to a chemotherapy nurse clinic for pre-chemotherapy assessment and counselling. During pre-chemotherapy assessment at the nurse clinic, patients are assessed on whether they understand and are suitable for home chemotherapy.

\section{CHALLENGES TO OVERCOME AND MOVING FORWARD Availability of Additional Chemotherapy Regimens for Home Infusion Delivery}

Because of the positive feedback received from patients and the positive impact on the healthcare system of the chemotherapy infusion at home model, the feasibility of including more drug regimens for ambulatory home infusion could be explored. There are other chemotherapy agents currently under investigation for home infusion. ${ }^{15,24}$

Under the partially at-home service model, agents that are administered over one to several days, with long stability ${ }^{25}$ and manageable toxicities are targeted. The most widely used agent is $5 \mathrm{FU}$, as the typical treatment runs over

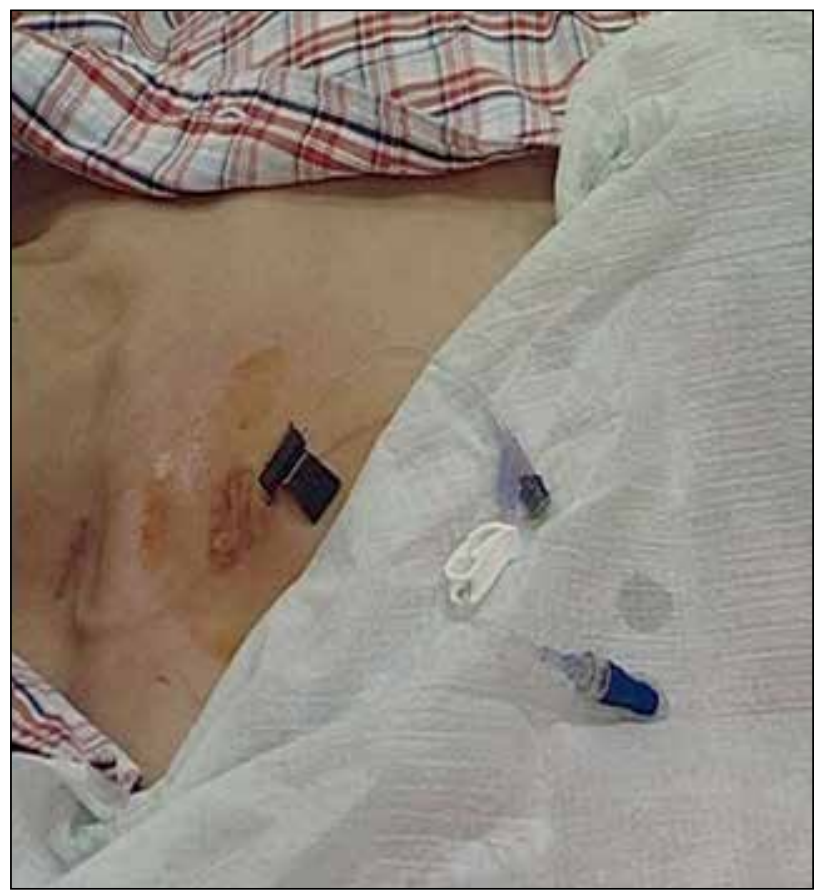

Figure 2. Implantable port must be accessed with a non-coring needle for infusion therapy.

46 hours or continuously with the patient's radiation therapy. There is room for extending $5 \mathrm{FU}$ home infusion to various other disease groups in addition to colorectal and pancreatic cancers by modifying the drug delivery procedures of inpatient infusion regimens. One possible example is 4-day carboplatin-5FU for gastric cancer with the 1-hour infusion of carboplatin administered in a day centre, followed by a 48 -hour at-home infusion of $5 \mathrm{FU}$, after which patients return to the day centre to resupply the pump for another 48-hour infusion. Another option is 5-day cisplatin-5FU for head and neck cancer, with the first-day regimen including 3-hour inpatient cisplatin infusion and rigorous hydration with mannitol, followed by a 48 -hour at-home infusion of $5 \mathrm{FU}$, and then repetition of the 48-hour infusion. Trabectedin ${ }^{26}$ is an antineoplastic agent that could potentially be switched from inpatient to home administration because its administration requires prolonged infusion over 24 hours. It has relatively low toxicity despite the fact that it is a vesicant, and the possibility of extravasation occurring at home has been largely prevented by CVAD pre-insertion.

Other advances have led to the development of further generations of multiple-channel and flexibly programmable pumps that can deliver temporally precise patterns of chemotherapy. ${ }^{27}$ Such pumps 
could allow complex chemotherapy regimens to be switched from the inpatient to the outpatient setting. Certain patients, especially those with support at home, can take home several doses of chemotherapy to be delivered by a programmable digital pump via a central line and then return for refills. In Europe, this change in the management of complex treatments has reduced the number of in-hospital days. ${ }^{28}$ Examples of patients who can benefit from this change include those with acute leukaemia who receive induction, reinduction, and consolidation chemotherapy infusions and patients with lymphoma who are conditioned with the BEAM regimen (carmustine [BCNU], etoposide, cytarabine and melphalan) prior to haematopoietic stem cell transplantation. Other initiatives could also be undertaken to encourage at-home administration of such treatments as pump-administered antibiotics. These facts and products have resulted in the rapid growth of a new home-care industry.

The possibility of chemotherapy infusion at home could be increased by calling for extra community care. Options for improvements include provision of at-home chemotherapy by a chemotherapy homecare nurse or community nurse after receiving training, at community centres, or in a mobile bus for chemotherapy care. ${ }^{29}$ Once the appropriate infrastructure is available, the totally athome model that is already popular for chemotherapy delivery in rural areas of some Western countries (eg, the United Kingdom, Canada) can be more widely implemented in Hong Kong. More chemotherapy drugs with relatively few toxicities and manageable sideeffects could be included for administration at home or community centres by chemotherapy nurses regardless of infusion duration. ${ }^{9}$

\section{Availability of Vascular Access Devices}

Throughout the management of at-home chemotherapy infusion, CVADs have a paramount role. The lack of a dedicated support team to provide reliable and adequate vascular access may be one of the reasons why some hospitals do not offer home chemotherapy. Besides vascular surgeons, other specialties could also be involved in performing CVAD placement, for example, interventional radiologists could perform PICC insertion, and general surgeons could place implantable ports. However, the specialties of general surgery and radiology also face increased pressure due to elevated demand for their services.

In many Western countries, mainland China, and Taiwan,
PICC insertion is commonly done by a properly trained nurse or PICC nurse in the day centre setting, which can free physicians for other clinical tasks while still maintaining quality service. ${ }^{30}$ Compared with the other CVAD types, insertion of a PICC is less invasive and relatively easy to perform, mainly requiring expertise in handling needles and guide wires and inserting catheters, which can be imparted through supervised training. ${ }^{31}$

\section{Strengthening Home Backup Support}

The centres that have implemented ambulatory home chemotherapy service in Hong Kong have not encountered major problems so far, as the centres continuously review and share their practices and have taken measures to prevent potential issues. In the future, to further expand services to more agents or regimens with wider toxicity coverage, more intensive and structured telephone follow-up with patients and their families is required. Accordingly, patients are always encouraged to get in touch over the phone if they have problems. Further, telehealth interventions for remote monitoring and management of chemotherapy side-effects may help providers to connect with patients at home ${ }^{32}$ Moreover, such interventions could help primary healthcare professionals or community/home care nurses with chemotherapy training to take on additional roles such as monitoring, supervising therapy, or home care support.

\section{CONCLUSION}

Modern chemotherapy using the ambulatory home infusion model became widely accepted with the development of CVADs and portable infusion devices. Providing sustainable service and staffing for ambulatory home chemotherapy requires several components. Protocol development, patient counselling, and emergency support are necessary. Such support should account for drug toxicity, the treatment's expected side-effects, and the self-care capabilities of the patient and family. Logistics should be established through multidisciplinary collaboration, chemotherapy nurse clinics, expertise development, and training. The chemotherapy infusion at home model for advanced cancer could be further promoted and developed by exploring at-home chemotherapy administration of additional drugs, identifying future opportunities for work with newer and more advanced practice foci, and training initiatives. Such training could involve CVAD placement and usage, telehealth system support, programmable digital pumps for complex chemotherapy regimens, and chemotherapy administration by chemotherapy nurses at the patient's home or community centre. Our future goal 
is to meet the needs for increasing service load and ongoing chemotherapy access to populations who need it.

\section{REFERENCES}

1. Hong Kong Cancer Registry, Hospital Authority, Hong Kong SAR Government. Overview of Hong Kong Cancer Statistics of 2017. Available from: https://www3.ha.org.hk/cancereg/pdf/overview/ Summary\%20of\%20CanStat\%202017.pdf. Accessed 13 Feb 2020.

2. Hospital Authority. Hospital Authority Strategic Service Framework for Cancer Services 2019. Available from: https://www. ha.org.hk/haho/ho/ap/HACANCERSSF_Eng.pdf. Accessed 6 Jun 2020.

3. Joo EH, Rha SY, Ahn JB, Kang HY. Economic and patient-reported outcomes of outpatient home-based versus inpatient hospital-based chemotherapy for patients with colorectal cancer. Support Care Cancer. 2011;19:971-8.

4. Corrie PG, Moody AM, Armstrong G, Nolasco S, Lao-Sirieix SH, Bavister $\mathrm{L}$, et al. Is community treatment best? A randomized trial comparing delivery of cancer treatment in the hospital, home and GP surgery. Br J Cancer. 2013;109:1549-55.

5. Evans JM, Qiu M, MacKinnon M, Green E, Peterson K, Kaizer L. A multi-method review of home-based chemotherapy. Eur J Cancer Care (Engl). 2016;25:883-902.

6. Tsui SL, Ng KF, Chan WS, Chan TY, Lo JR, Yang JC. Cancer pain management: experience of 702 consecutive cases in a teaching hospital in Hong Kong. Hong Kong Med J. 1996;2:405-13.

7. Grayson ML, Silvers J, Turnidge J. Home intravenous antibiotic therapy: a safe and effective alternative to inpatient care. Med J Aust. 1995;162:249-53.

8. Hitchcock J, Jepson AP, Main J, Wickens HJ. Establishment of an outpatient and home parenteral antimicrobial therapy service at a London teaching hospital: a case series. J Antimicrob Chemother. 2009;64:630-4.

9. Boothroyd L, Lehoux P. Home-based chemotherapy for cancer: issues for patients, caregivers and the health care system. Montreal QC: Agence d'Evaluation des Technologies et des Modes d'Intervention en Sante (AETMIS); 2004. Available from: https://www.inesss.qc.ca/fileadmin/doc/AETMIS/Rapports/ Cancer/2004_02_en.pdf. Accessed 11 Feb 2020.

10. Young AM, Kerr DJ. Home delivery: chemotherapy and pizza? BMJ. 2001;322:809-10.

11. Corbett M, Heirs M, Rose M, Smith A, Stirk L, Richardson G, et al. The delivery of chemotherapy at home: an evidence synthesis. Southampton (UK): NIHR Journals Library; 2015.

12. Anderson H, Addington-Hall JM, Peake MD, MKendrik J, Keane K, Thatcher N. Domiciliary chemotherapy with gemcitabine is safe and acceptable to advanced non-small-cell lung cancer patients: results of a feasibility study. Br J Cancer. 2003;89:2190-6.

13. Polinski JM, Kowal MK, Gagnon M, Brennan TA, Shrank WH. Home infusion: safe, clinically effective, patient preferred, and cost saving. Healthc (Amst). 2017;5:68-80.

14. Haute Autorité de santé. Conditions du développement de la chimiothérapie en hospitalisation à domicile: analyse économique et organisationnelle, Haute Autorité de Santé. mise en ligne janvier 2015 [in French]. Available from: https://www.has-sante.fr/upload/ docs/application/pdf/2015-03/conditions_du_developpement_de_ la_chimiotherapie_en_hospitalisation_a_domicile_-_rapport.pdf. Accessed 13 Feb 2020.

15. Lüthi F,Fucina N,Divorne N, Santos-Eggimann B, Currat-Zweifel C, Rollier $\mathrm{P}$, et al. Home care - a safe and attractive alternative to inpatient administration of intensive chemotherapies. Support Care Cancer. 2012;20:575-81.

16. Lee YM, Hung YK, Mo FK, Ho WM. Comparison between ambulatory infusion mode and inpatient infusion mode from the perspective of quality of life among colorectal cancer patients receiving chemotherapy. Int J Nurs Pract. 2010;16:508-16.

17. Mak S, Yih P. Expert Opinion. Ambulatory home chemotherapy programme - a success story. MIMS Oncology Hong Kong. Available from: https://specialty.mims.com/topic/ambulatoryhome-chemotherapy-programme---a-success-story--. Accessed $11 \mathrm{Feb} 2020$

18. Lee WM. Safety and acceptance of home ambulatory chemotherapy. Paper presented at: Hospital Authority Convention 2019;2019 May 14-15; Hong Kong.

19. Sydnor ER, Perl TM. Hospital epidemiology and infection control in acute-care settings. Clin Microbiol Rev. 2011;24:141-73.

20. Eichinger S. Cancer associated thrombosis: Risk factors and outcomes. Thromb Res. 2016;140 Suppl:S12-7.

21. Bak K, Gutierrez E, Lockhart E, Sharpe M, Green E, Costa S, et al. Use of continuous infusion pumps during radiation treatment. J Oncol Pract. 2013;9:107-11.

22. Salman D, Biliune J, Kayyali R, Ashton J, Brown P, McCarthy T, et al. Evaluation of the performance of elastomeric pumps in practice: are we under-delivering on chemotherapy treatments? Curr Med Res Opin. 2017;33:2153-9.

23. Mak SS. Oncology nursing in Hong Kong: milestones over the past 20 years. Asia Pac J Oncol Nurs. 2019;6:10-6.

24. Lal R, Hillerdal GN, Shah RN, Crosse B, Thompsone J, Nicolson M, et al. Feasibility of home delivery of pemetrexed in patients with advanced non-squamous non-small cell lung cancer. Lung Cancer. 2015;89:154-60.

25. Benizri F, Bonan B, Ferrio AL, Brandely ML, Castagné V, Théou-Anton N, et al. Stability of antineoplastic agents in use for home-based intravenous chemotherapy. Pharm World Sci. 2009;31:1-13.

26. Schöffski P, Cerbone L, Wolter P, De Wever I, Samson I, Dumez $\mathrm{H}$, et al. Administration of 24-h intravenous infusions of trabectedin in ambulatory patients with mesenchymal tumors via disposable elastomeric pumps: an effective and patient-friendly palliative treatment option. Onkologie. 2012;35:14-7.

27. Hrushkesky WJ. Home-based circadian-optimized cancer chemotherapy. In: Berner B, Dinh SM, editors. Electronically Controlled Drug Delivery. Florida: CRC Press; 2019. p 9-46.

28. Fridthjof KS, Kampmann P, Dünweber A, Gørløv JS, Nexø C, Friis LS, et al. Systematic patient involvement for homebased outpatient administration of complex chemotherapy in acute leukemia and lymphoma. Br J Haematol. 2018;181:637-41.

29. Chu H. Is Hong Kong ready for home chemotherapy? MIMS Oncology Hong Kong. 13 Dec 2016. Available from: https://today. mims.com/is-hong-kong-ready-for-home-chemotherapy. Accessed $17 \mathrm{Feb} 2020$.

30. Walker G, Todd A. Nurse-led PICC insertion: is it cost effective? Br J Nurs. 2013;22(19 Suppl):S9-15.

31. Jenkins LC. PICC nurses in practice. Radiology Today Magazine. 2009;10:5.

32. Breen S, Ritchie D, Schofield P, Hsueh YS, Gough K, Santamaria N, et al. The Patient Remote Intervention and Symptom Management System (PRISMS) - a Telehealth-mediated intervention enabling real-time monitoring of chemotherapy side-effects in patients with haematological malignancies: study protocol for a randomised controlled trial. Trials. 2015;16:472. 